\title{
Al7075 Alaşımına Uygulanan Dekoratif Krom Kaplama Tabakasının Karakterizasyonu
}

\author{
Sema Ayyıldız ${ }^{1}$, Temel Varol ${ }^{2 *}$, Gençağa Pürçek ${ }^{3}$ \\ ${ }^{1}$ Trabzon Silah Sanayi, Ar-Ge Merkezi, 61080, Trabzon, Türkiye \\ ${ }^{2}$ Karadeniz Teknik Üniversitesi, Mühendislik Fakültesi, Metalurji ve Malzeme Mühendisliği Bölümü, Trabzon, \\ Türkiye \\ ${ }^{3}$ Karadeniz Teknik Üniversitesi, Mühendislik Fakültesi, Makine Mühendisliği Bölümü, Trabzon, Türkiye \\ soayyildiz@gmail.comiD,*tvarol@ktu.edu.triD,purcek@ktu.edu.tr \\ Makale gönderme tarihi: 05.10.2020, Makale kabul tarihi: 27.04.2021
}

\begin{abstract}
$\ddot{\mathbf{O} z}$
Bu çalışmada, Al7075 alaşımından üretilen tabanca gövdesine uygulanan dekoratif kaplama aşamaları incelenerek alaşım yüzeyinde oluşturulan kaplama tabakasının özellikleri araştırılmıştır. Dekoratif krom kaplama aşamaları olan çinko, bakır, nikel ve krom kaplama sonucu oluşan kaplama tabakası kalınlıkları ve kaplama işlemi sonucu yüzey pürüzlülüğündeki değişimler incelenmiştir. Kaplamaların mikroyapısı ve yüzey morfolojisi taramalı elektron mikroskobu (SEM) ile incelenmiştir. Elde edilen sonuçlar, Al7075 alaşım yüzeyleri üzerindeki Zn, Cu, Ni ve Cr kaplama tabakalarının homojen olduğunu göstermiştir. Kaplama türü çinko kaplamadan krom kaplamaya değişirken, kaplama kalınlığı ise 5 $30 \mu \mathrm{m}$ arasında artmıştır. Sonuç olarak, tabanca gövdesinde kullanılan Al7075 alaşım yüzeyine dekoratif krom kaplama tabakası, diğer kaplama yöntemlerine kıyasla çok daha kısa sürede ve çok daha düşük maliyetli olan elektrolitik kaplama yöntemi kullanılarak sentezlenmiştir.
\end{abstract}

Anahtar Kelimeler: A17075, dekoratif krom kaplama, elektrolitik kaplama, kaplama kalınlığı, yüzey pürüzlülüğü

\section{Characterization of Decorative Chrome Coating Layer Applied to Al7075 Alloy}

\begin{abstract}
In this study, the decorative chromium coating process was applied to the gun body produced from Al7075 alloy, and the properties of the coating layer formed on the alloy surface were investigated in detail. The coating layer thicknesses formed as a result of zinc, copper, nickel and chrome plating and the change in the surface roughness as a result of the process were examined. The microstructure and surface morphology of coating were investigated by means of a scanning electron microscope (SEM). Surface roughness of coated samples was determined by a contact profilometer (MasSurf 1 MAHR) at a high sensitivity setting. Obtained results show that the $\mathrm{Zn}, \mathrm{Cu}, \mathrm{Ni}$ and $\mathrm{Cr}$ coating layers on the A17075 alloy surfaces was found to be mainly homogeneous. Coating thickness increased from 5 to $30 \mu \mathrm{m}$, while changing the coating type from $\mathrm{Zn}$ to $\mathrm{Cr}$. As a result, decorative chrome coating was successfully applied to the Al7075 alloy using electrolytic coating method with lower cost and shorter time compared to the other coating methods.
\end{abstract}

Keywords: Al7075, coating thickness, decorative chromium coating, electrolytic coating, surface roughness

\section{GíRiş}

Çelik esaslı malzemelere nazaran oldukça düşük yoğunluğa sahip olmaları, düşük ergime sicaklığından kaynaklanan kolay üretim özelliği ve yüksek özgül dayanımlarından dolayı Al ve alaşımları otomotiv ve havacılık endüstrisinde yaygın bir şekilde kullanılmaktadır (Zhang 2017; Dursun 2014). Bununla birlikte, $\mathrm{Al}$ ve alaşımları düşük yüzey sertlikleri ve dolayısıyla zayıf aşınma dirençlerinden dolayı özellikle aşınmaya maruz kalan uygulamalarda kullanılmamaktadırlar. Bu nedenle $\mathrm{Al}$ ve alaşımlarının aşınmaya maruz kalacakları uygulamalar için yüzey kaplama yöntemleri ile yüzeylerinin aşınmaya dirençli hale getirilmesi gerekmektedir. $\mathrm{BN}$ ve TiN gibi nitrürler, $\mathrm{Al}_{2} \mathrm{O}_{3}$ gibi oksit ve $\mathrm{SiC}$, $\mathrm{TiC}$ ve $\mathrm{B}_{4} \mathrm{C}$ gibi karbür şeklinde $\mathrm{Al}$ 
yüzeylere uygulanan kaplamalar ile Al ve alaşımlarının yüzey özellikleri geliştirilerek bu malzemelerin kullanım alanları genişletilebilmektedir. Bununla birlikte nitrür, oksit ve karbür türü bileşikler ile Al esaslı malzemeler arasındaki termal uyumsuzluklar, kimyasal bağ yapısı ve mekanik dayanım farklılıkları sebebiyle kaplama tabakasını oluşturmak oldukça maliyetli olmakta ve bu tür kaplama tabakaları uzun ömürlü olamamaktadır (Chakravarthy 2012; Wang 2014).

Yüksek maliyet, özel kaplama cihazlarının gereksinimi, kaplama yüzeyi ile kaplama tabakası arasındaki uyumsuzluklar ve uzun ömürlü olmayan kaplama tabakası gibi olumsuzlukları ortadan kaldırarak Al ve alaşımlarının yüzeyini aşınmaya karşı dirençli hale getirmek için uygulanabilecek en etkin yöntem yüzeylerin krom kaplanmasıdır. Yüksek ergime sıcaklığı, mükemmel korozyon ve oksidasyon direnci ve yüksek sertliği nedeniyle krom, alüminyum yüzeylerin kaplanması için eşsiz bir metaldir. Krom ayrıca iyi aşınma ve korozyon direnci kombinasyonunu sağladığı için çelik malzeme yüzeylerinin de kaplamasında siklıkla kullanılmaktadır. Alüminyum ve çelik yüzeylerin krom kaplanmasinda kutu sementasyon, fiziksel buhar biriktirme, kimyasal buhar biriktirme ve elektroliz yöntemleri kullanılmaktadır (Wang 2017; Jaing 2019). $\mathrm{Bu}$ yöntemler arasında bulunan elektrolitik krom kaplama yöntemi kaplanan yüzey boyunca homojen krom kaplama tabakasının elde edilebilmesi, üretim kolaylığı ve düşük maliyeti sebebiyle öne çıkmaktadır (Liang 2017).

Elektrolitik dekoratif veya sert krom kaplama kalitesini kaplama işlemi öncesi kaplanacak yüzeye uygulanan pürüzlendirme, temizleme ve yağlama işlemlerinin kalitesi ile kaplama prosesi parametreleri olan kaplama çözeltisi bileşen oranları, kaplama çözeltisi sıcaklığı, akım değeri ve anot-katot arası mesafe belirlemektedir. Kir ve Apay (2020) tarafindan yapılan bir çalışmada düşük karbonlu çelik üzerinde elektrolitik yöntemle oluşturulan sert krom kaplamanın özellikleri üzerine işlem parametrelerinin etkisi araştırılmıştır. $\mathrm{Bu}$ çalışmanın sonuçlarına göre en iyi kaplama sertlik değerine, $40 \mathrm{Amp} \mathrm{dm}{ }^{2}$ akım yoğunluğu, $60^{\circ} \mathrm{C}$ sicaklık ve $100 \mathrm{~mm}$ anot-katot arası mesafede ulaşılmış ve kaplama banyo sıcaklığının artması ile birlikte numunelerdeki sertlik değeri ve aşınma dirençlerinin arttığı gözlemlenmiştir. Deepak vd. (2019) tarafindan yapılan bir çalışmada ise A588 çelik malzemesi üzerine elektrolitik kaplama yöntemi ile $\mathrm{Cu}, \mathrm{Cr}$, Ni ve $\mathrm{Zn}$ kaplanarak farklı kaplama tabakalarının yüzey sertliği, kaplama kalınlığı ve korozyon direnci üzerine etkileri araştırılmıştır. Çalışma sonuçlarına göre en yüksek kaplama sertliği ve en iyi korozyon direnci $\mathrm{Cr}$ kaplı çelik numunelerde elde edilmiştir. Yukarıda sonuçları verilen çalışmalardan da anlaşılacağı üzere elektrolitik krom kaplama genellikle çelik malzemeler üzerine uygulanmakta ve krom kaplama bu malzemeleri aşınmaya, oksidasyona ve korozyona karşı korumaktadır. Bununla birlikte Al alaşımlarından olan ve savunma ve havacılik uygulamalarında yaygın olarak kullanılan A17075 alaşımının dekoratif krom kaplaması ile ilgili literatür bilgisi oldukça sınırlıdır. Bundan dolayı bu çalıșmanın amacı; özellikle hafif silah gövdelerinde de sıklıklar kullanılan Al7075 alaşımının dekoratif amaçlı krom kaplanması ve krom kaplama işlemi sonucunda elde edilen kaplama tabakasının özelliklerinin karakterize edilmesidir.

\section{DENEYSEL ÇALIŞMALAR}

Bu çalışma kapsamında dekoratif krom kaplama uygulanan A17075 alaşımının \% kimyasal kompozisyon bileşimi sırasıyla $0.19,0.12,1.7,0.08$, 2.5, 5.8, 0.2, $0.04 \mathrm{Fe}, \mathrm{Si}, \mathrm{Cu}, \mathrm{Mn}, \mathrm{Mg}, \mathrm{Zn}, \mathrm{Cr}$, Ti ve kalan şeklinde Al içermektedir. Elektrolitik dekoratif krom kaplama işlemine başlamadan önce kaplama hazırlık aşamaları olan polisaj, kumlama ve yağ alma gibi ön işlemler numuneye uygulanarak Al7075 tabanca gövde yüzeyi temizlenmiștir. Kumlama sonras1 A17075 tabanca gövde yüzeyine ait SEM görüntüleri Şekil 1'de görülmektedir.

$\mathrm{Bu}$ şekilde uygulanan pürüzlendirme işlemi, kumlama işlemi sonrasında elde edilen yüzey, kaplama tabakası ile altl1k malzemesi olan A17075 yüzeyi arasında iyi bir ara yüzey oluşumu için oldukça önemlidir. Yüzeyi temizlenerek kaplama işlemi için hazır hale getirilen numuneler $\% 50$ nitrik asit içeren çözeltiye daldırılmış ve daha sonra durulama işlemi uygulanarak kaplama çözeltisi tatbikine hazır hale getirilmiştir. Şekil 2.a'da numune daldırma aparatına ait resimde görüldüğü gibi aynı anda çok sayıda parçaya kaplama işlemi uygulanabilmektedir. Al7075 alaşımından üretilen tabanca gövdesine uygulanan dekoratif kaplama aşamaları Şekil 2.b'de görülmektedir. *Bu aşamadan 
sonra A17075 alaşımından üretilen tabanca gövdesine uygulanan dekoratif krom kaplama işlemindeki ilk adım olan zinkat olarak adlandırılan yüzeyin çinko ile kaplanması adımıdır. Çinko kaplama tabakasının A17075 altl1k üzerine uygulanan ilk kaplama yüzeyini oluşturması ve diğer kaplama tabakaları için arayüzey görevi görmesinden dolayı bu işlem iki kez tekrarlanarak gözeneksiz ve numune yüzeyi boyunca düzgün bir çinko kaplama tabakasının elde edilmesi amaçlanmıştır. Çinko kaplama işlemini takiben durulama işlemi uygulanmış ve akabinde bakır

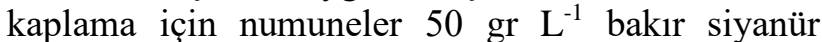
$(\mathrm{CuCn})$ ve $20 \mathrm{gr} \mathrm{L}^{-1}$ sodyum siyanür içeren bakır kaplama banyosuna daldırılarak bakır kaplama işlemi gerçekleştirilmiştir.
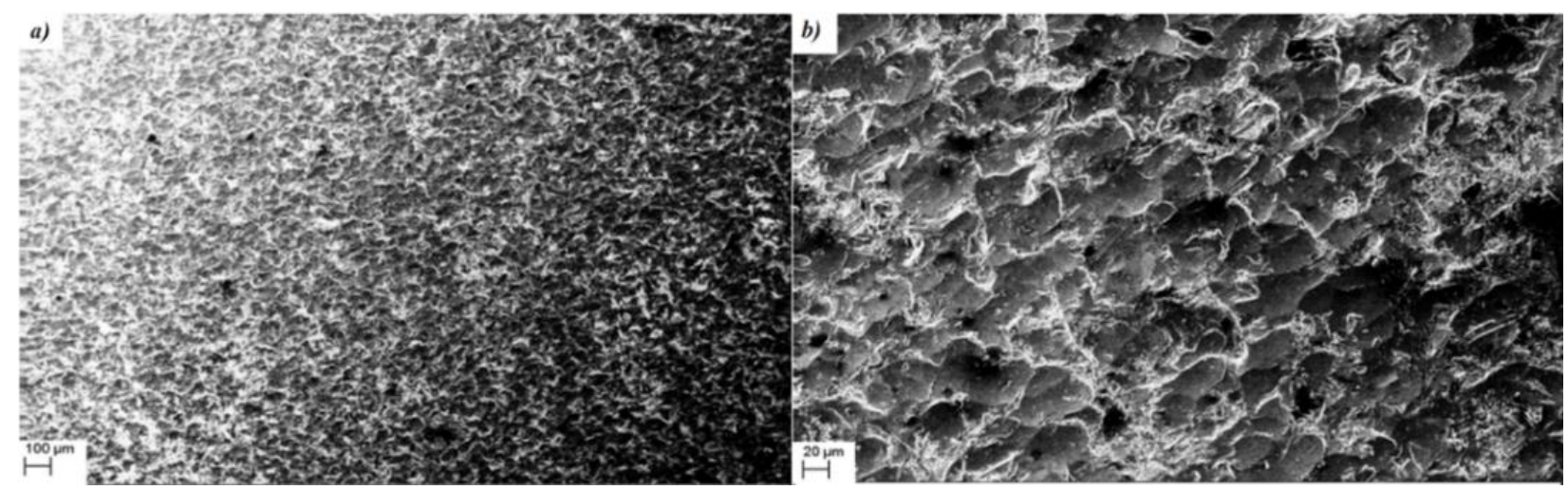

Şekil 1. Al7075 malzemesinden işlenen tabanca gövde yüzeyine uygulanan kumlama işlemi sonrası yüzey morfolojisini gösteren SEM resimleri; (a) Düşük büyütme ve (b) Yüksek büyütme
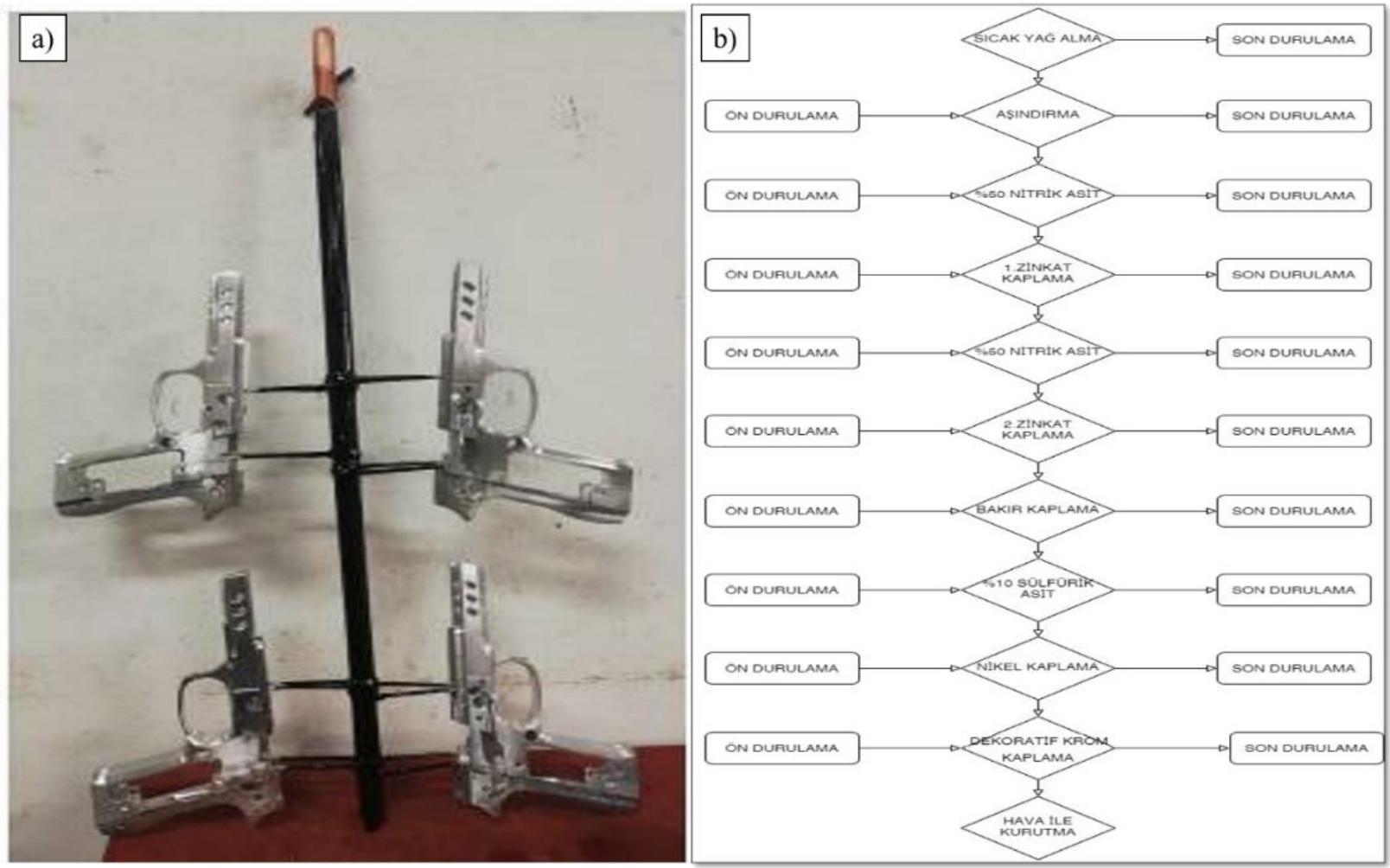
Şekil 2. Dekoratif krom kaplama için kullanılan numune daldırma aparatı (a) ve Al7075 alaşımından üretilen tabanca gövdesine uygulanan dekoratif kaplama aşamalarını gösteren akış diyagramı (b)

Bakır kaplama işleminden sonra numunelere; durulama + sülfirik asitli çözeltiye daldırma + durulama işlemleri uygulanmış ve bu durumda 60 gr/lt nikel klorür $\left(\mathrm{NiCl}_{2}\right), 300 \mathrm{gr} \mathrm{L}^{-1}$ nikel sülfat $\left(\mathrm{NiSO}_{4}\right)$ ve $40 \mathrm{gr} \mathrm{L}^{-1}$ borik asit $\left(\mathrm{H}_{3} \mathrm{BO}_{3}\right)$ içeren nikel kaplama banyosuna daldırılarak nikel kaplama işlemi tamamlanmıştır. Nikel kaplama işlemi tamamlandıktan sonra durulama işlemi uygulanmış ve numuneler $250 \mathrm{gr} \mathrm{L}^{-1}$ kromik asit $\left(\mathrm{H}_{2} \mathrm{CrO}_{4}\right)$ ve $2 \mathrm{gr}$ $\mathrm{L}^{-1}$ sülfürik asit $\left(\mathrm{H}_{2} \mathrm{SO}_{4}\right)$ içeren krom kaplama banyosuna daldırılarak krom kaplama işlemi gerçekleştirilmiştir. Dekoratif krom kaplama işleminde her bir kaplama işleminde kullanılan sıcaklık, akım yoğunluğu ve anot-katot arası mesafe değerleri Tablo 1'de verilmiştir.

Tablo 1. Dekoratif krom kaplama işleminde her bir kaplama işleminde kullanılan işlem parametreleri

\begin{tabular}{|c|c|c|c|c|c|}
\hline Kaplama Türü & Sıcaklık $\left({ }^{\circ} \mathrm{C}\right)$ & $\begin{array}{c}\text { Akım } \\
\text { Yoğunluğu } \\
(\text { Amp dm }\end{array}$ & $\begin{array}{c}\text { Anot-Katot arası } \\
\text { mesafe (mm) }\end{array}$ & $\mathrm{pH}$ & Süre (sn) \\
\hline Çinko Kap. & 25 & - & - & 13.2 & 30 \\
\hline Bakır Kap. & 60 & 2 & 260 & 11 & 300 \\
\hline Nikel Kap. & 60 & 4 & 280 & 4.3 & 300 \\
\hline Krom Kap. & 40 & 10 & 260 & 0 & 300 \\
\hline
\end{tabular}

Şekil 3 incelendiğinde dekoratif krom kaplama prosesine ait kaplama adımları olan çinko, bakır, nikel ve krom kaplama işlemlerinin uygulandığ kaplama banyolarına ait resimler görülmektedir. 

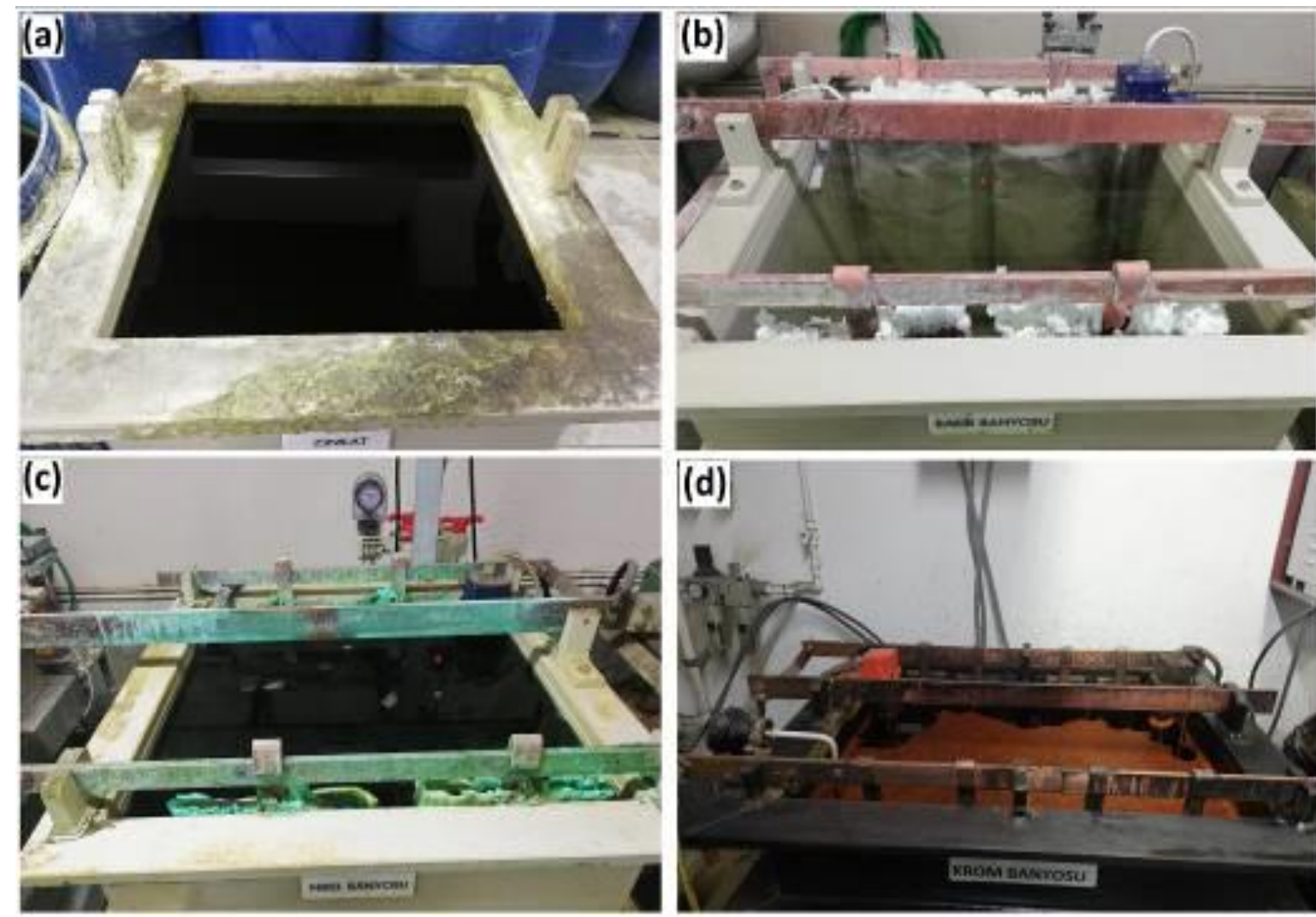

Şekil 3. Dekoratif krom kaplama prosesinde kullanılan kaplama banyoları; (a) çinko, (b) bakır, (c) nikel ve (d) krom kaplama banyosu

Dekoratif krom kaplanmış A17075 tabanca yüzeyinde oluşturulan her bir kaplama tabakasına ait içyapı incelemesi ve kaplama kalınlığının belirlenmesi ile ilgili incelemeler Zeiss Evo LS10 marka taramalı elektron mikroskobu (SEM) kullanılarak yapılmıştır. Yoğunluk değerleri Arşimet deneyi ile ölçülmüştür. Arayüzey incelemeleri PANalytical marka ve $\mathrm{X}^{\prime}$ Pert $^{3}$ Pro model X 1 şını kırınım cihazında $20^{\circ}-100^{\circ}$ aralığında adımı $0.01^{\circ}$ olacak şekilde araştırılmıştır. Numunelerin mikrosertlik incelemeleri Vickers sertlik ölçüm yöntemleriyle 10 sn süre ve 10 gr yük koşullarında belirlenmiştir. Yüzey pürüzlülüğü ölçümleri ise TT211, TIME Group, USA marka yüzey pürüzlülüğü ölçüm cihazı kullanılarak ölçülmüş olup sertlik ve yüzey pürüzlülüğü ölçümleri için üç değerin ortalaması dikkate alınmıştır.

\section{BULGULAR VE TARTIŞMA}

\section{Mikroyapı ve Kaplama Kalınlığı}

Şekil 4'de dekoratif krom kaplama aşamaları olan çinko, bakır, nikel ve krom kaplama tabakalarına ait mikroyapı resimlerini içermektedir (Şekil 4 a-d). Mikroyap1 resimlerinden de anlaşıldığ kaplama aşaması sonucu elde edilen kaplama tabakasının Al7075 yüzeyi boyunca farklı kalınlıklarda ancak homojen bir şekilde oluştuğu görülmektedir. Şekil 4.d'de görüldüğü gibi Al7075 altlık üzerindeki nihai kaplama kalınlığ $30 \mu \mathrm{m}$ değerine kadar ulaşmaktadır. Her bir kaplama aşaması sonucunda elde edilen kaplama tabakası kalınlığ 1 değerlerinin farklı olmasının sebebi, kaplama tabakası olarak elde edilen elementin kaplama işleminde farklı karakteristik özelliklere sahip olmasıdır.

\section{Elementel Analiz}

A17075 altlık yüzeyinden başlayıp kaplama yüzeyini de içini alacak şekilde elementel analiz resimleri Şekil 4'de verilmiştir (Şekil 4 e-g). 


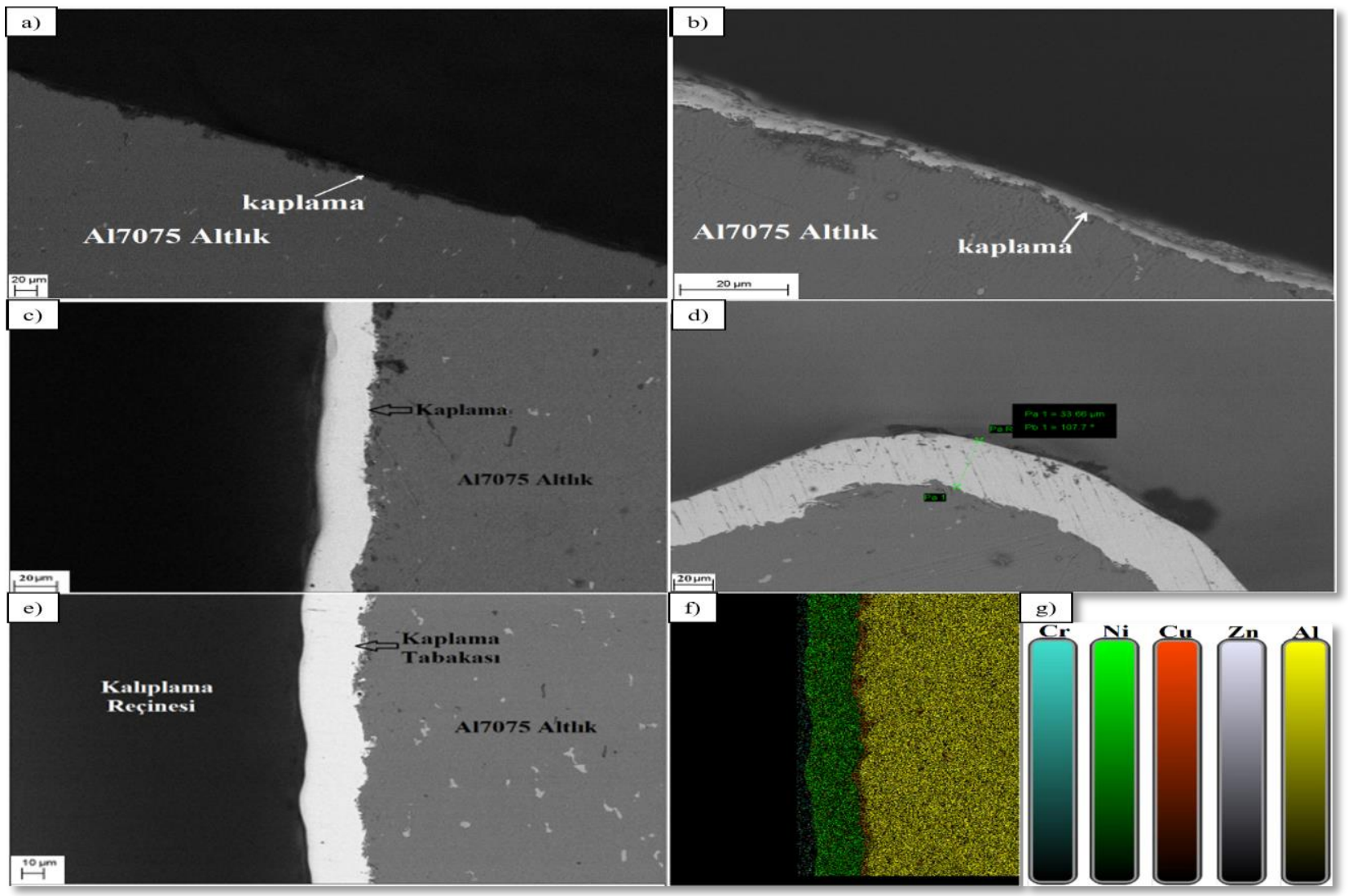

Şekil 4. Dekoratif krom kaplama işleminde her bir kaplama aşamasına ait kesit resimleri; (a) Çinko kaplama, (b) Bakır kaplama, (c) Nikel kaplama ve (d) Krom kaplama ve Dekoratif krom kaplama için elementel haritalama; (e) Kaplama tabakasına ait BSD görüntüsü ve (f) kaplama tabakası üzerinden yapılan elementel haritalama ve (g) elementlerin renk skalaları

Elementel analiz resmi dekoratif krom kaplama aşamaları olan çinko, bakır, nikel ve krom kaplama tabakalarını içermektedir. Kaplama tabakaları arasında en yüksek kaplama tabakası kalınlığı Nikel kaplama tabakasına aittir ve bunun nedeni kaplama hücresi içindeki akım yoğunluğu ve kaplama süresinin elektrolitik nikel kaplama işlemi için yüksek olmasıdır. Nikel kaplama tabakası, malzemeye kazandırmış olduğu yüksek korozyon direnci ve sertlik değerinde artış göstermesi nedeniyle kaplamanın özelliklerini önemli oranda etkilemektedir. Ayrıca son kaplama tabakası olan krom yüzeyi için de önemli bir ara yüzey oluşturmaktadır. Nihai kaplama tabakasını oluşturan krom yüzey ise Al7075 altlık yüzeyine mükemmel bir parlaklık ve yüksek oksidasyon direnci sağlayarak silah gövdesinin görsel cazibesini, aşınma ve çizilmeye karşı direncini arttırmaktadır.Şekil 5'de Al7075 altlık yüzeyi ve kaplama tabakası üzerinden alınan noktasal elementel analiz sonuçları görülmektedir. Noktasal elementel analiz sonuçları haritalama ile elde edilen element dağılımını doğrular nitelikte olup Al7075 altlık yüzeyi üzerine dekoratif krom kaplama uygulamasinın uygun $\mathrm{Zn}, \mathrm{Cu}$ ve $\mathrm{Ni}$ kaplama tabakaları sayesinde başarılı bir şekilde kaplandığını göstermektedir. 1 nolu analiz bölgesi kaplama tabakasının en üst katman bölgesinden alınmış olup Şekil 5b'de görüldüğü gibi bütün kaplama bileşenlerini içermektedir. 2 nolu analiz bölgesi en büyük katman kalınlığına sahip Ni katmanı üzerinden alınmış olup $\% 100 \mathrm{Ni}$ varlığını işaret ederken 3 nolu analiz bölgesi altlık yüzeyine çok yakın bir bölgeden seçildiği için $\mathrm{Al}$ ve $\mathrm{Zn}$ elementlerinin varlığını ortaya koymuştur (Şekil 5c- 
d). Şekil 5d ise altlık malzemesi olan A17075 yüzeyi üzerinden alınmış olup $\mathrm{Al}$ elementi varlığ görülmektedir.

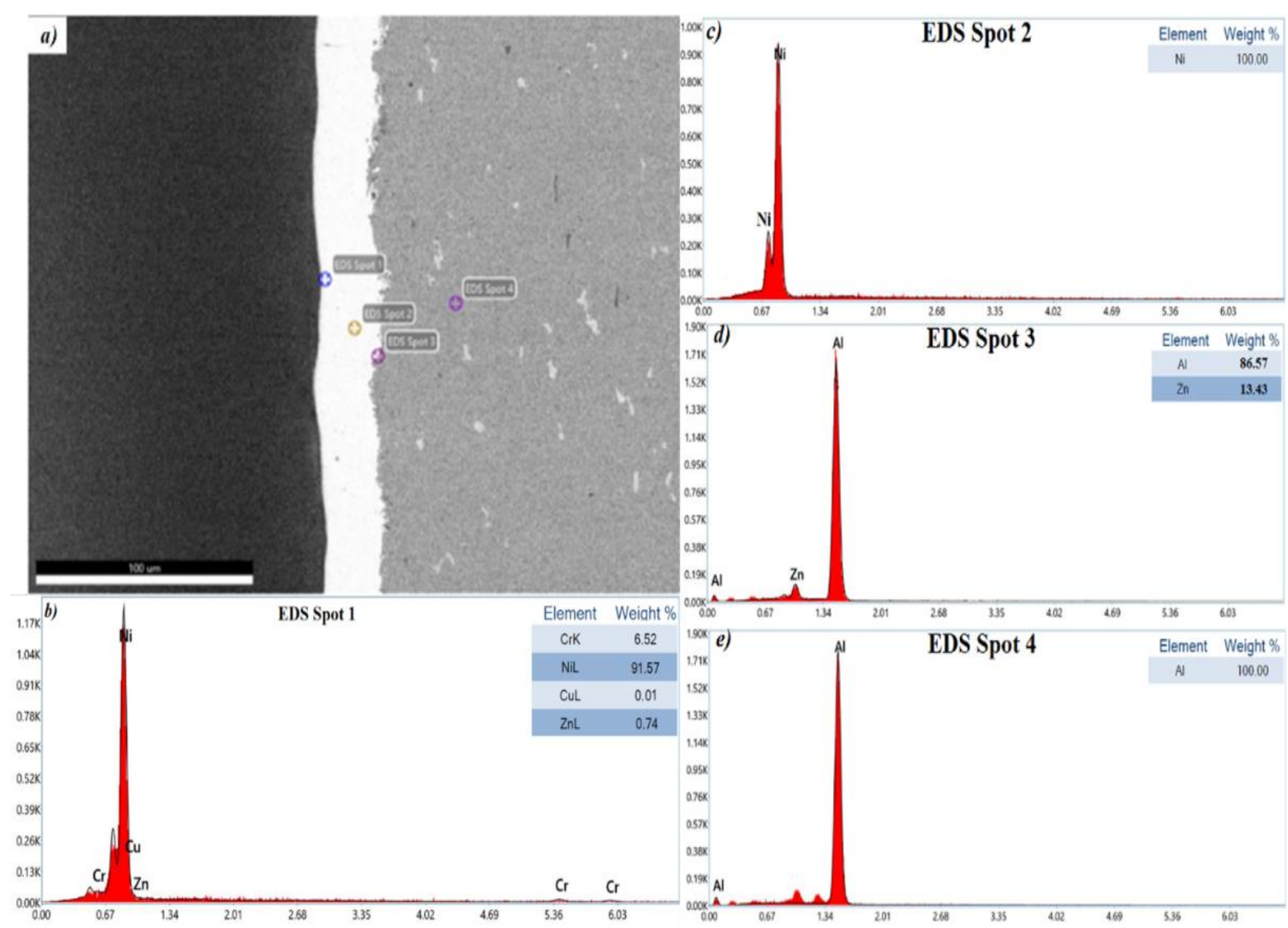

Şekil 5. Dekoratif krom kaplama ve Al7075 altlık yüzeyi için noktasal elementel analiz sonuçları; (a) Noktasal elementel analiz bölgeleri, (b) EDS Spot 1, (c) EDS Spot 2, (d) EDS Spot 3 ve (e) EDS Spot 4

\section{Mikrosertlik}

A17075 altl1k ve kaplama tabakası üzerinden alınan sertlik değerlerine ait piramit iz alanını içeren SEM görüntüsü Şekil 6'da verilmiştir. Dekoratif krom kaplama içerdiği nikel ve krom kaplama tabakaları sayesinde A17075 altlık yüzeyine kıyasla daha sert bir yüzey oluşturmakta ve sonuçta A17075 yüzeyini aşınma ve çizilmeye karşı dirençli kılmaktadır. Yapılan sertlik ölçümleri sonucunda A17075 altl1k yüzeyine ait ortalama sertlik değerlerinin 75 HV olduğu, kaplama tabakasına ait ortalama sertlik değerlerinin ise $130 \mathrm{HV}$ olduğu belirlenmiştir. Bu sonuç dekoratif krom kaplamanın Al7075 tabanca gövdesine iyi bir korozyon direnci ve parlaklık kazandırmasına ek olarak yüzey sertliğini de geliştirdiğini ortaya koymaktadır. Dekoratif krom kaplama işlemi sonucunda elde edilen krom tabakası sertlik değerinin sert krom kaplama ile kıyaslandığında daha düşük olmasının nedeni dekoratif krom kaplama işlemi sonucunda elde edilen kaplama tabakası kalınlığının daha az olması ve pürüzlülük ve gözenek içeriğinin daha fazla olmasıdır. 


\section{Yüzey Pürüzlülüğü}

Tablo 2'de sirasıyla kumlama, zinkat, bakır, nikel ve krom kaplama işlemleri sonucunda ölçülen ortalama pürüzlülük değerleri verilmiştir. Ölçüm sonuçlarına göre ortalama pürüzlülük değerleri 1 $\mu$ m'nin üzerindedir ve bu durum son işlem olarak uygulanan dekoratif krom kaplama için yüksek bir değerdir. Bu sonuç kaplama tabakaları ile A17075 altlık malzemesi arasında iyi bir arayüzey oluşturmak için uygulanan kumlama işlemi sonucunda yüzeyde oluşan pürüzlülüklerin (Ra: $1.5 \mu \mathrm{m})$ azaltılması gerektiğini ortaya koymaktadır.

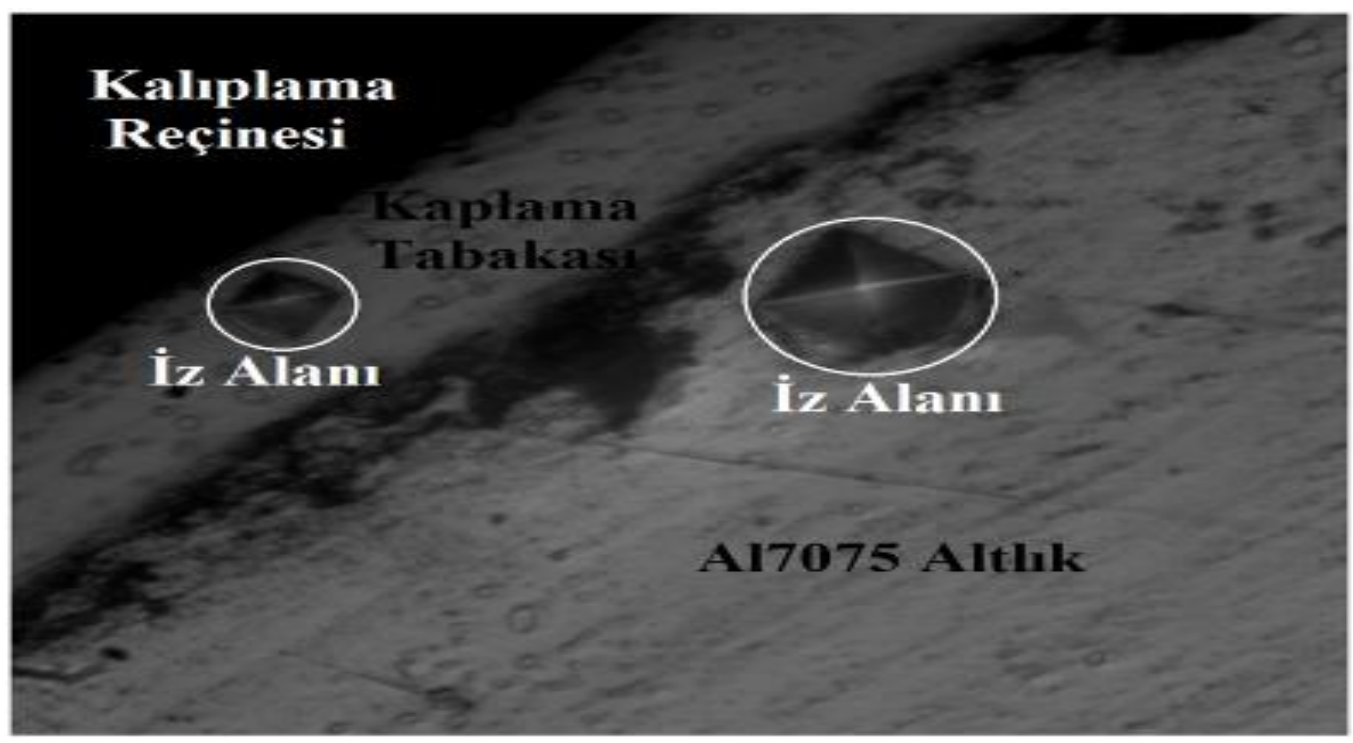

Şekil 6. Altlık ve kaplama tabakası üzerinde sertlik iz alanları (40X büyütme)

Tablo 2. Dekoratif krom kaplama aşamalarına ait ortalama pürüzlülük değerleri

\begin{tabular}{|c|c|c|c|c|}
\hline \multirow{2}{*}{} & \multicolumn{4}{|c|}{ Kaplama Türü } \\
\cline { 2 - 5 } & Çinko & Bakır & Nikel & Krom \\
\hline Ortalama Pürüzlülük $(\mu \mathrm{m})$ & 1.461 & 1.231 & 1.202 & 1.185 \\
\hline
\end{tabular}

\section{SONUÇLAR}

Çalışma kapsamında Al7075 altlık yüzeyi üzerine elektrolitik kaplama yöntemi ile dekoratif kaplama uygulanmış ve kapsamlı olarak yapılan mikroyapı karakterizasyon çalışmaları ile kaplama tabakası karakterize edilmiştir. Bu çalışmada elde edilen genel sonuçlar aşağıda özetlenmiştir:
1) Al7075 altlık yüzeyi üzerine elektrolitik kaplama yöntemi ile yüzey boyunca homojen dağılımlı bir kaplama tabakası elde edilmiştir.

2) $\quad \mathrm{Al} 7075$ altlık malzemesi üzerinde sentezlenen nihai kaplama kalınlığ $25-30 \mu \mathrm{m}$ aralığındadır.

3) Elementel haritalama resimlerine göre kaplama tabakası içerisinde en fazla katman kalınlığına sahip tabaka nikel kaplama tabakasıdır. 
4) Mikrosertlik değeri ölçüm sonuçlarına göre A17075 altlık malzemesi üzerinde $75 \mathrm{HV}$ olarak ölçülen sertlik değeri kaplama tabakası yüzeyinde $130 \mathrm{HV}$ değerine yükselmiştir. Böylelikle dekoratif krom kaplama ile Al7075 altlık aşınma direnci geliştirilmiştir.

5) Yapılan kaplama sonucu $1 \mu \mathrm{m}$ civarında bir yüzey pürüzlülüğü $(\mathrm{Ra})$ değeri elde edilmiştir. $\mathrm{Bu}$ değerin hala yüksek olduğu ve bunun düşürülmesine dönük çalışmaların yapılması gerekmektedir. Bunun temel nedeninin kaplama öncesi uygulanan yüzey hazırlama ișlemleri olduğu ve bu ișlem parametrelerinin de optimize edilmesi gerektiği değerlendirilmiştir.

\section{TEŞEKKÜR}

Tabanca gövdesine uygulanan kaplama çalıșmaları TISAȘ Ar-Ge Merkezi bünyesinde bulunan elektrolitik kaplama ünitelerinde gerçekleştirilmiştir. Bu çalışmaya her türlü desteği veren TİSAŞ firmasına teşekkür ederiz.

\section{CIKAR CATISMASI BEYANI}

Yazar/ Yazarlar bu makale ile ilgili herhangi bir çıkar çatışması bildirmemektedir.

\section{ARAŞTIRMA VE YAYIN ETİĞİ BEYANI} Yazar/Yazarlar bu çalışmanın araştırma ve yayın etiğine uygun olduğunu beyan eder.

\section{KAYNAKLAR}

Liang, Aimin \& Li, Yuwen \& Liang, Hongyu \& Ni, Liwei \& Zhang, Junyan. (2016). A Favorable Chromium Coating Electrodeposited from Cr(III) Electrolyte Reveals Anti-wear Performance Similar to Conventional Hard Chromium. Materials Letters. 189. https://doi.org/10.1016/j.matlet.2016.12.022.

Gudla, Visweswara \& Chandran, Maneesh \& Bhattacharya, Subramshu \& Rao, M S \& Kamaraj, M.. (2012). A comparative study on wear behavior of TiN and diamond coated WC-Co substrates against hypereutectic Al-Si alloys. Applied Surface Science. $261 . \quad 520 \quad 527$. https://doi.org/10.1016/j.apsusc.2012.08.049.

Fanyong Zhang, Mufu Yan, Jining He, Fuxing Yin. (2017). Microstructures and nano-mechanical properties of multilayer coatings prepared by plasma nitriding $\mathrm{Cr}$ coated Al alloy, Vacuum, Volume 142, Pages 106113, ISSN 0042-207X, https://doi.org/10.1016/j.vacuum.2017.05.013.
Kır, H, Apay, S . (2020). Elektrolitik Yöntemle Sert Krom Kaplanan Yapı Çeliğinde Kaplama Parametrelerinin Taguchi Metodu ile Optimizasyonu . Gümüşhane Üniversitesi Fen Bilimleri Enstitüsü Dergisi , 10 (1), 7-14. https://doi.org/10.17714/gumusfenbil.540183

James Raj, J R Deepak \& Raja, V. \& Kaliaraj, Gobi. (2019). Mechanical and Corrosion Behavior of $\mathrm{Cu}, \mathrm{Cr}$, $\mathrm{Ni}$ and $\mathrm{Zn}$ Electroplating on Corten A588 Steel for Scope for Betterment in Ambient Construction Applications. Results in Physics. 14. 102437. https://doi.org/10.1016/j.rinp.2019.102437.

Jie, Jiang \& Hu, Jianjun \& Yang, Xian \& Guo, Ning \& Xu, Hongbin \& Li, Hui \& Jin, Yan \& Yu, Hongbing. (2019). Microstructure and annealing behavior of $\mathrm{Cr}$ coatings deposited by double glow plasma on AISI 5140 steel. Results in Physics. 15. 102674. https://doi.org/10.1016/j.rinp.2019.102674.

Wang, Jun-Hua \& Du, Mao-Hua \& Han, Fu-Zhu \& Yang, Jing. (2014). Effects of the ratio of anodic and cathodic currents on the characteristics of micro-arc oxidation ceramic coatings on Al alloys. Applied Surface Science. 292. https://doi.org/10.1016/j.apsusc.2013.12.028.

Wang, Qin-Ying \& Behnamian, Yashar \& Luo, Hong \& Wang, Xian-Zong \& Leitch, Michael \& Zeng, Hongbo $\&$ Luo, Jing-Li. (2017). Anticorrosion performance of chromized coating prepared by pack cementation in simulated solution with $\mathrm{H} 2 \mathrm{~S}$ and $\mathrm{CO} 2$. Applied Surface Science. 419. https://doi.org/10.1016/j.apsusc.2017.05.001.

Dursun, Tolga \& Soutis, Constantinos. (2014). Recent developments in advanced aircraft aluminium alloys. Materials \& Design. 56. 862-871. https://doi.org/10.1016/j.matdes.2013.12.002. 